\title{
Towards adequately framing sustainability goals in research projects: the case of land use studies
}

\author{
Gabriela Wuelser
}

Received: 8 April 2013/ Accepted: 5 November 2013/Published online: 1 December 2013

(c) The Author(s) 2013. This article is published with open access at Springerlink.com

\begin{abstract}
Sustainability-oriented undertakings employ a multitude of different definitions and understandings of the term sustainable development. Against this background, the question of which sustainability goals to refer to at project level must be posed. This article discusses this question using the example of research on land use issues. It presents a qualitative in-depth empirical analysis of the underlying sustainability understanding of research projects, and identifies crucial characteristics of the ways researchers deal with the respective normative goals. The notions of sustainable development advanced by such projects featured different foci with respect to the overall meaning of the concept and were influenced by diverse actor and stakeholder perspectives. Further, the identified sustainability conceptions were deliberated on to different extents, and also differed with respect to whether they were explicit or contextualized. Most importantly, the projects differed in how they broached the issue of sustainability goals as part of research. The findings were used to develop a set of guidelines that clarifies how research can be related successfully to the societal vision of sustainable development. The guidelines draw conceptually on general requirements for appropriate sustainability conceptions derived from the Brundtland definition. They offer a tool for reflecting on one's assumptions with respect to sustainability goals at any stage of research, which is crucial for advancing the seminal field of sustainability science.
\end{abstract}

Handled by Richard Bawden, Systemic Development Institute, Australia.

\section{G. Wuelser $(\bowtie)$}

Institute for Environmental Decisions, ETH Zurich, CHN H

70.1, Universitaetstrasse 16, 8092 Zurich, Switzerland

e-mail: gabriela.wuelser@env.ethz.ch

URL: http://www.envphil.ethz.ch
Keywords Sustainability research · Sustainability conceptions - Normative principles $\cdot$ Science-policy nexus $\cdot$ Grounded theory $\cdot$ Science studies

\section{Introduction}

Since the Rio Summit in 1992, governments across the globe have decided to strive for sustainable development as originally outlined by the Brundtland Commission (WCED 1987). Related to these political commitments, a multitude of sustainability-oriented projects, policies, programs and the like have been developed and implemented. Such undertakings are, by declaration, concerned with changing less sustainable ways of meeting needs to something more sustainable-which requires being able to tell good and bad practices apart. To avoid being arbitrary, the corresponding value judgments need to be based on distinct normative principles. In the case of sustainability, these principles are inherent in the actual interpretation of sustainable development used in each case. However, conceptions of sustainability can diverge considerably, whether they are based on the same or different underlying principles (Jacobs 1999). While being of general importance, the issue of sustainability conceptions that underlie concrete projects is explored here using the example of scientific research.

Conceiving the meaning of sustainable development is not without controversy. On the one hand, a plurality of sometimes strongly differing and even competing meanings has been ascribed to this term (Lafferty and Langhelle 1999; Lélé 1991; Redclift 1992; Schultz et al. 2008; Sneddon et al. 2006). On the other hand, sustainable development is a term that has been defined only vaguely (e.g., Fergus and Rowney 2005; Kates et al. 2005; 
Robinson 2004). This may explain to some degree why people do not necessarily mean the same things when alluding to the concept. In addition, adopted meanings are not necessarily apparent. Thus, more often than not, particular sustainability understandings used in practice remain implicit (Pohl et al. 2010b).

These difficulties do not stop at scientific research. When framed as undertakings that aim to support societal change, scientific knowledge is targeted and context-sensitive (Grunwald 2004). This is where values with respect to sustainability objectives unavoidably come in. However, as long as researchers continue to struggle with the meaning of this concept (e.g., Cerin and Scholtens 2011) and underestimate the importance of defining the respective values in their work (Miller 2013), the relationship between research and societal sustainability objectives remains blurry. So far, studies on sustainability science projects (e.g., Pohl et al. 2010a; Wiek et al. 2012) have not focused on the notions of sustainability advanced by such research. In-depth empirical analyses that explore to what understandings and principles sustainabilityoriented research refers, and in how far these understandings can be regarded as appropriate, are lacking to date. However, as long as this issue is not properly addressed, projects run the risk of being based on inappropriate underlying sustainability conceptions, and consequently of producing results that may be useless, miss the views and priorities of affected people or even promote unsustainable propositions in the problem context. Clarifying inherent sustainability ideals is therefore expected to provide a basis for evaluating the sustainability conceptions of research projects.

The present article explores qualitatively how sustainable development is framed in scientific projects, and elaborates what can be learned from the characteristics identified from the project data in order to adequately handle sustainability notions in research. It draws thereby on general requirements for appropriate sustainability conceptions based on the Brundtland definition-the most broadly approved definition of sustainable development to date, which features core development requirements as also highlighted in other definitions. This empirical study thus pursued the following questions:

(1) In what way do research projects refer to particular sustainability goals? Do researchers underpin their projects with specific notions about what to strive for? If yes, what are these and in what respects do they vary? How can ways in which researchers deal with such normative goals be characterized?

(2) Do the identified characteristics inform the appropriateness of how sustainability goals are framed in research projects? What can be derived from this towards a more general evaluation of sustainability conceptions in research projects?
In the following, a set of basic requirements for appropriate sustainability conceptions is suggested, conceptually clarifying what the general idea of sustainable development implies for concrete projects. The methods applied for empirically exploring and normatively interpreting how research projects frame sustainability goals are then introduced. The results section presents the sustainability conceptions found as well as their attributes, which describe how the investigated land use studies dealt with this normative concept. In the discussion, the implications of the results for framing appropriate sustainability conceptions of research projects are illustrated. The article concludes by pointing out a few crucial aspects with respect to the issue in a wider context.

\section{Requirements for appropriate sustainability conceptions based on the Brundtland definition}

A sustainability conception is understood here as a particular vision, notion, understanding, or ideal of a sustainable development in the context of a real world problem situation. It may be expressed as a set of goals or objectives, or as descriptions of a desired or ideal state, development or as a way of meeting needs to be striven for. In the following, a set of conceptual adequacy requirements for sustainability conceptions is suggested. It is based on the normative principles included in the Brundtland definition (WCED 1987).

The Brundtland report provided the most broadly approved definition of sustainable development to date. This has been reconfirmed politically by many international agreements referring to the respective definition as a baseline (cf. The Future We Want-Outcome document of Rio+20; United Nations Millennium Declaration; Johannesburg Declaration; Rio Declaration). Accordingly, this definition has also been the one most quoted in the scientific literature (Kates et al. 2005). Its inherent basic normative principles can be summarized as the three core objectives of

(1) environmental integrity;

(2) intra-generational equity; and

(3) intergenerational equity (Wuelser et al. 2012).

Each of these entails a number of crucial elements, such as the world's poor being able to meet their essential needs, or the effects of our activities being absorbable by the biosphere (Table 1). Most importantly, the core objectives are strongly interrelated and thus should not be treated in isolation from each other (WCED 1987, 4). Poverty alleviation programs are generally not independent of ecosystem health. In fact, concrete projects, policies, activities or any sort of sustainability-oriented undertakings may 
Table 1 Core objectives of sustainable development as deduced from the Brundtland definition (WCED 1987) and their elements, further developed from Wuelser et al. (2012)

\begin{tabular}{|c|c|c|}
\hline Core objective & Elements & Sources \\
\hline \multirow[t]{3}{*}{ A. Environmental integrity } & 1. To sustain the natural resource base & WCED 1987, pp 44/45, 57-60 \\
\hline & $\begin{array}{l}\text { 2. To shape policies and practices in ways that allow the } \\
\text { biosphere to absorb their effects }\end{array}$ & WCED 1987, p 8, (58) \\
\hline & $\begin{array}{l}\text { 3. To keep a balance between use and transformation of } \\
\text { environmental systems and their protection and restoration }\end{array}$ & WCED 1987, pp. 45, 133 \\
\hline \multirow[t]{4}{*}{ B. Intra-generational equity } & $\begin{array}{l}\text { 1. To ensure that all members of the present generation are able } \\
\text { to meet their needs, especially that the world's poor can meet } \\
\text { their basic or essential needs }\end{array}$ & WCED 1987, pp. 44, 47 and 54 \\
\hline & $\begin{array}{l}\text { 2. To ensure that all members of the present generation, } \\
\text { especially the world's poor, can access the constrained } \\
\text { natural resource base }\end{array}$ & WCED 1987, pp. 40,43 \\
\hline & $\begin{array}{l}\text { 3. To support distributing costs and benefits of development } \\
\text { fairly within the present generation }\end{array}$ & WCED 1987, pp. 43, 52 \\
\hline & $\begin{array}{l}\text { 4. To that end, to allow distributing economic and political } \\
\text { power fairly so that participation in decision-making and } \\
\text { democratic processes is not hindered }\end{array}$ & Boyce 1994; WCED 1987, pp. 38, 46-49, 63, 65 \\
\hline \multirow[t]{3}{*}{ C. Inter-generational equity } & $\begin{array}{l}\text { 1. To keep the ability of future generations to meet their needs } \\
\text { intact (as far as is in one's power) }\end{array}$ & WCED 1987, pp. $43,57,63$ \\
\hline & $\begin{array}{l}\text { 2. To allow for allocating resources fairly between present and } \\
\text { future generations }\end{array}$ & Jabareen 2008; WCED 1987, pp. 45/46 \\
\hline & $\begin{array}{l}\text { 3. To allow distributing costs and benefits of development } \\
\text { equitably among the present and future generations }\end{array}$ & Brown Weiss 1989; WCED 1987, p. 46 \\
\hline
\end{tabular}

need to focus on single core objectives or aspects thereof, e.g., gender inequality, income maintenance or river pollution. Nevertheless, they should do so against the background of a critical assessment of the potential implications on other core objectives in order to avoid negative side effects. Further, trade-offs among the core objectives may be necessary in many cases. According to the Brundtland definition, these are tolerable as long as they do not compromise the ability of others to meet their needs or pass respective environmental limitations (WCED 1987, 43). Indeed, decisions on both foci and acceptable trade-offs always need to be made in reference to case-specific particularities.

On a project level, sustainability conceptions or visions may represent context specific interpretations of a general definition. However, even when relating to the same issue, interpretations of sustainable development can vary considerably because people's opinions about where to go or what to strive for can differ strongly, even fundamentally. According to Jacobs, (1999) this plurality of possible meanings in a particular case is due to sustainable development being a so-called contestable political concept (Gallie 1956). Contested concepts such as democracy or fairness include, on the one hand, a general or abstract level of meaning which is "unitary but vague", as well as, on the other hand, a specific or concrete level of meaning featuring a number of plural and contested interpretations (Jacobs 1999, 25). Whereas the abstract level of meaning corresponds to a general, mostly broadly approved, definition like that promoted by the Brundtland Commission, the plurality of context specific, more concrete interpretations are to be attributed to the specific level of meaning. This implies that, when it comes to concrete cases, sustainability conceptions can be shaped in various-equally reasonable-ways. Thus, at the project level, what development to strive for is not self-evident but requires a normative decision. If this decision is to be made in accordance with the Brundtland report, it should be the result of participatory negotiation processes yielding visions and goals that are ideally shared by the various relevant actor and stakeholder groups and serve the common good. In other words, reflecting these people's perspectives, understandings and views is a necessary condition for serving the common good: "The law alone cannot enforce the common interest. It principally needs community knowledge and support, which entails greater public participation in the decisions that affect the environment" (WCED 1987, 63). Relevant actors and stakeholders can be identified by looking for people who have power and interests (Mitchell et al. 1997) as well as expertise related to an issue (Collins and Evans 2002; Enengel et al. 2012; Thompson and Scoones 2009; Wynne 1991).

Adequate sustainability conceptions are thus, on the one hand, visions, notions, ideals or sets of goals that serve the general core objectives of sustainable development while not having any unacceptable negative implications on any 
of these objectives. On the other hand, adequate sustainability conceptions reflect the perspectives of the relevant actors and stakeholders. This adds up to:

(1) Considering the core objectives of sustainable development and their interrelations as a first requirement, and

(2) Reflecting the relevant actors and stakeholders' perspectives as a second requirement for adequate sustainability conceptions at project level.

In practice, appraising sustainability goals requires examining to what extent existing-and potentially conflicting - visions about what to strive for address and affect the overall or core objectives of sustainable development. Ideally, the two adequacy requirements are reconciled, i.e., people's visions brought into agreement with the core objectives. For research, this implies essentially verifying whether one's project refers to a particular position and, where required, adapting it correspondingly. Note that adding a core objective to the vision to which a research project refers does not imply that this objective also needs to form an object of research. Similarly, considering relevant actors' perspectives does not necessarily demand participatory research approaches.

\section{Methods}

Research approach

A qualitative approach based on the methodology of grounded theory was applied to investigate empirically how researchers referred to sustainable development in their projects. This allowed concepts of how researchers deal with sustainability goals to be derived from empirical data instead of starting from a given theory. Decisive factors for choosing this approach included the fact that sustainability notions are expected to be based on subjective perceptions (Evely et al. 2008), can be contextsensitive (Merriam 1990), and do not necessarily need to be entirely evident to researchers themselves. As noted in the Introduction, little information and theory can be found on the topic, which suggests a need to explore the issue in a qualitative way (Creswell 1994). Qualitative approaches allow clarification of meanings as perceived by people and formulated by them in their own words (Denzin and Lincoln 2005). The methodology of grounded theory was applied in order to be open to all of the many of ways in which sustainable development is framed and handled in research projects as well as to develop these respective concepts during the course of the study (Corbin and Strauss 2008; Glaser and Strauss 1967).
Sample of projects

The study focused on recent research projects on land use issues that were led, at least partly, by Swiss researchers in order to build a basis for potential longer-term research collaborations in Switzerland. The sample consisted of ten current or recently completed projects that aimed explicitly to contribute to sustainable development and that were concerned with a concrete societally relevant issue. Importance was attached to compiling a heterogeneous set of projects within Swiss natural and social scientific research on land use questions. This allowed identifying commonalities and differences (Patton 1990, cited in Morse 1994). Accordingly, the selected projects differed with respect to (1) the economic development context in which the research was conducted (industrialized and developing countries), (2) the disciplines involved (natural and social scientific), (3) the form of research conducted (basic, applied, inter- and transdisciplinary), (4) the form of knowledge generated [systems, target and transformation knowledge as further developed by Pohl and Hirsch Hadorn (2007)], and (5) project size (Table 2).

\section{Data collection}

Semi-structured interviews, research proposals and notes from informal meetings were used as sources of data. Over a period of 1.5 years and following the principles of theoretical sampling (Corbin and Strauss 2008; Glaser and Strauss 1967), 12 full and 4 complementing interviews were conducted, taking 40-110, and 30-50 min, respectively. Up to three researchers per project were interviewed based on their involvement in setting up and concretizing the project. Among the full interviews, seven were conducted with PhD students, and six with post-docs or senior scientists. The complementing short interviews were made with the supervising professors to capture their perspectives as well. Depending on the mother tongue of the interviewees, the interviews were held in Swiss German, German or English. All interviews were fully recorded and transcribed.

Investigating sustainability understandings was one aspect of a broader study on how researchers conceive research for sustainable development. With respect to sustainability visions, the interviewees were asked to describe (1) the sustainability problem situation their projects referred to; (2) how they personally judged that situation with respect to sustainability; (3) what their personal, general understanding of sustainable development was; and (4) what conception of sustainable development or sustainable land use underlay the project from their point of view. As the interview guide developed over time, the questions posed changed slightly during the 
Table 2 Sample of research projects investigated consisting of single $\mathrm{PhD}$ studies except for MOUNT (cluster project including ten PhD studies in nine different research groups), BFUEL (consisting of two PhD studies) and AQUA (consisting of four PhD studies and a synthesis study)

\begin{tabular}{|c|c|c|c|}
\hline $\begin{array}{l}\text { Project acronym (number of } \\
\text { interviews) }\end{array}$ & Project (short title) & Discipline/field & Country \\
\hline CARB (2) & Carbon sequestration potential & Ecosystem Sciences & Panama \\
\hline MOUNT (2) & $\begin{array}{l}\text { Land use in mountain regions } \\
\text { (MOUNTLAND) }\end{array}$ & $\begin{array}{l}\text { Various natural and Social Science } \\
\text { fields }\end{array}$ & Switzerland \\
\hline FOR (2) & Drought impacts on forest development & (Forest) Ecology & Switzerland \\
\hline POLL (2) & Ecosystem service pollination & Ecology & India \\
\hline LIV (1) & Forest and livelihoods & Forestry and Development & Madagascar \\
\hline PALM (1) & Oil palm expansion & (Applied) Ecology & Indonesia \\
\hline WAT (2) & Water-related environmental services & Physical Geography & Kenya/Tanzania \\
\hline LEG (1) & Crop-livestock systems & Plant Nutrition & Nicaragua \\
\hline BFUEL (3) & $\begin{array}{l}\text { Biofuel crop production: debates and } \\
\text { impacts }\end{array}$ & Sociology and Human Geography & Ethiopia \\
\hline AQUA (3) & Water stress and management options & Human and Physical Geography & Switzerland \\
\hline
\end{tabular}

course of the study and thus were not entirely identical in all interviews.

Data analysis

The text parts of transcripts and proposals featuring statements on, or related to, sustainability visions were coded with respect to their content (problem statement, ideal, advocated action, etc.) and characteristics. Constant comparison (Corbin and Strauss 2008; Glaser and Strauss 1967) was used to elaborate the projects' sustainability conceptions (see Table 3) while differentiating between the researchers' personal opinions, general definitions and the visions the projects referred to. Constant comparison was also applied for identifying the characterizing properties of the sustainability conceptions as well as for developing the categories that they form. For studying whether and how these properties relate to the appropriateness of sustainability conceptions, a normative analysis was conducted (cf. "Discussion"). It was based on the conceptual requirements outlined above.

\section{Results: Sustainability conceptions in research projects}

Investigating how the research projects were orientated at sustainability goals yielded on the one hand insights into the content of advanced sustainability visions, and on the other a number of attributes that characterize how the researchers dealt with the challenge of referring their work to a societal concern. The identified distinctions presented below represent ideal typical simplifications in Weber's sense of what in reality are smooth transitions. Such ideal types are constructed models of real phenomena highlighting the aspects of interest (Hirsch Hadorn 1997; Weber 1973).

Contents of sustainability conceptions

The analyzed research projects were all found to refer to particular sustainability understandings. The identified notions about what to strive for that were underlying the projects mostly highlighted certain aspects of sustainable development in the context of the investigated issue (Table 3). Notions featuring a focus on environmental integrity (for future generations), an environmentdevelopment combination or a comprehensive conception can be discerned. The projects' notion had been determined by the researchers themselves, or clearly represented visions of third parties, such as, for example, of a larger program they were part of. In terms of their substance, the conceptions were found to reflect different actors' views and positions. In the following, the identified sustainability conceptions are discussed with respect to the overall objectives of sustainable development, as well as with respect to the actor perspectives they took up.

\section{Consideration of the core objectives of sustainable development}

As pointed out above, considering the general meaning of sustainable development includes assessing the possible implications of current or future practices on its core objectives. The contents of the research projects' conceptions were therefore analyzed on the basis of the crucial elements of the three core objectives (A-C, see Table 1), using the following questions: 


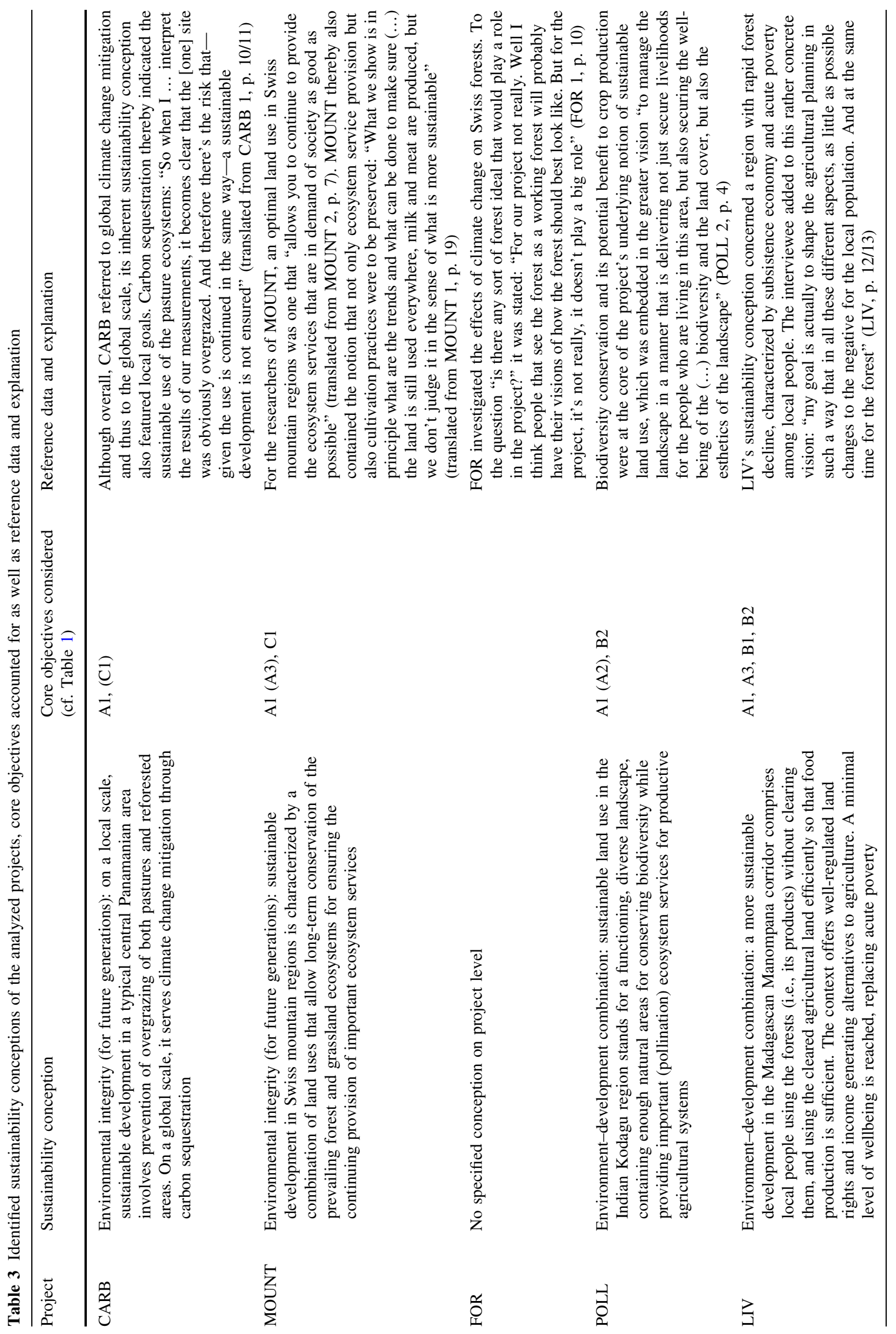




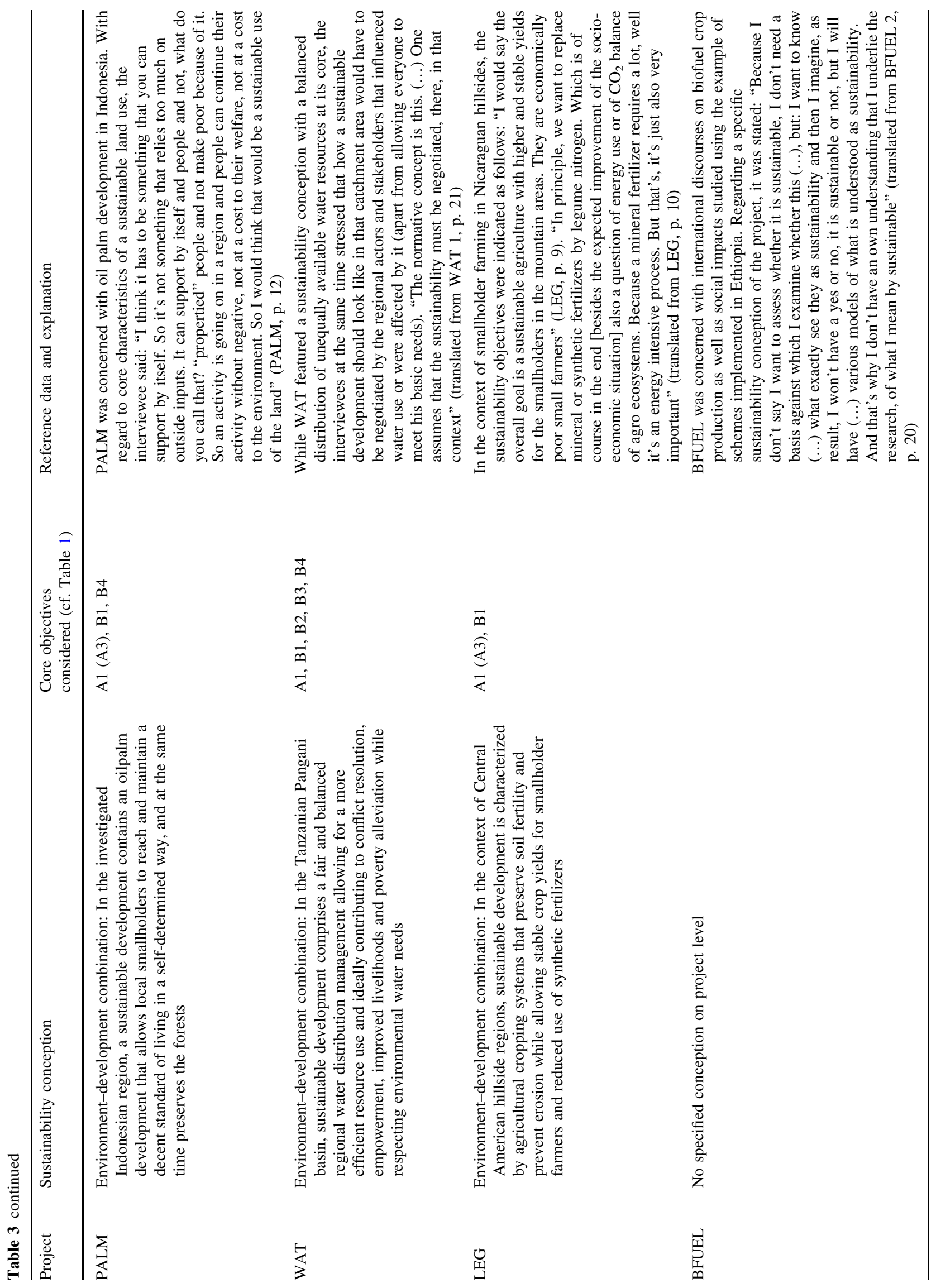




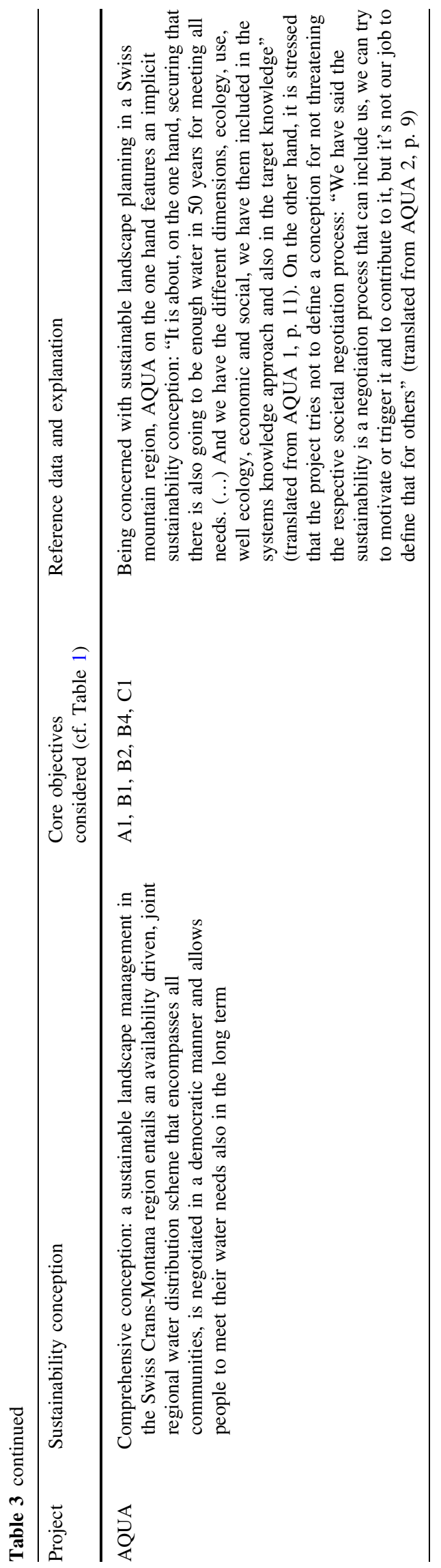

(1) Which core objectives of sustainable development are addressed directly by the sustainability conception, i.e., which core objectives are targeted?

(2) With respect to which core objectives are implications of activities considered?

Analogous to the identified focus on environmental integrity (for future generations), environment-development combination and comprehensive conception, the projects' sustainability conceptions were found to either combine environmental integrity with intergenerational equity or intra-generational equity elements, or feature crucial elements of all three core objectives. Thus, on a project level, the identified sustainability conceptions focused on a single core objective, on a combination of two core objectives, or considered all of them. Whereas the identified foci and combinations might be somewhat typical for research on land use issues, other foci and combinations are equally imaginable.

Environmental integrity (for future generations) Projects that advanced sustainability notions focusing on environmental integrity (for future generations) used predominantly natural scientific research approaches. Depending on the state of the ecosystems in question, the main concerns ranged from conserving ecosystems and their services through more sustainable land use forms, to restoring them. Implications of advocated actions on other core objectives to some extent concerned intergenerational equity. In being directed at future ecosystem service provision, the notion of MOUNT for example entailed not only an ecological focus, but also a concern for future generations: it addressed their ability to meet their needs in ways that allowed preservation of the prevailing ecosystems providing important services.

Environment-development combination Another group of projects' sustainability conceptions addressed both environmental integrity and intra-generational equity. These projects combined mostly natural with social scientific approaches and were conducted in developing countries. They represented the often-quoted integration of environmental and development concerns (e.g. van Egmond and de Vries 2011). LIV for example advocated balancing forest conversion and protection by combining a resource-conserving use of remaining forest areas with the goal of local inhabitants' ability to meet their basic needs, especially food security. It did not address intergenerational equity directly, although this concern might have been resonating to some extent as well.

Comprehensive conception Comprehensive sustainability conceptions addressed all three core objectives directly. This encompassed, for example, addressing the ability of future generations to meet their water needs and at the 
same time striving for an equitable distribution of water resources and political power on the landscape scale while avoiding water overuse to maintain ecosystem functioning (AQUA). This conception was also observed to be very general and inclusive. The researchers intended to consciously beware of indicating a concrete vision of regional landscape management.

No specified conception on project level Some researchers stressed that their project was not based on any specified conception of sustainable development. In these cases, it was indicated that a conception was thought to exist on a higher-ranking level of the research program a project was part of (e.g., FOR). Or sustainability models, positions and worldviews of different actors and actor groups built the actual object of research, which implied that, for reasons of scientific standards, the project did not take or advance a position itself (e.g., BFUEL).

\section{Consideration of relevant actors' and stakeholders' perspectives}

The sustainability goals advanced in the projects featured differing formative perspectives, i.e., were based on-or had taken up-different actors' views and positions.

These formative perspectives were identified and evaluated on the basis of the following questions:

(1) Whose perspectives are taken up by the sustainability conception?

(2) Are the respective actors and stakeholders the relevant ones with respect to sustainable development? Who else could have been relevant?

The sustainability conceptions were found to either dominantly reflect the researchers' own perspective (corresponding to their personal position), to take up a particular societal actor's perspective, or to consider the perspectives of various societal actors. Note that the number of considered actors does not necessarily correlate with the relevance of their perspectives. Thus, a fourth type-not found among the investigated sample-would comprise notions that entail the views of a large number of actors that are not necessarily or only partly relevant.

Researcher(s)' own perspective In some cases, the sustainability conceptions corresponded largely to the researchers' personal appraisal of the situation. Only very few of the researchers involved in these projects made a distinction between personal judgment and the projects' underlying conception, leaving the difference rather unnoticed. There was little or no indication of any considered actor or stakeholder perspective. The reasoning tended towards assuming that notions of what would be sustainable were largely obvious and widely shared. Consequently, whose perspectives to consider for identifying the sustainability notion to advance was not an issue.

Particular societal actor's perspective A particular societal actor's perspective taken up in a sustainability ideal covers either a single societal actor or an actor group, i.e., a collective actor. The question of whether other actors or stakeholders would have been important does not seem to arise, while the relevance of the selected actor is depicted as being very obvious. $\mathrm{CARB}$, for instance, referred to the discourse of the nation states participating in the UNFCC process, including the national government of Panama (Wolf et al. 2011). Interestingly, the perspective of local land users also became apparent to some degree during this research. It was added to the sustainability notion put forth with respect to the use of pasture ecosystems. While the international community of states participating in the UNFCC process was certainly crucial, the full perspective of the local people would have become relevant only in the case that advice with respect to a national afforestation scheme was given.

Perspectives of various societal actors Some projects featured sustainability conceptions that contained the views and perspectives of various crucial actors and stakeholders. The respective researchers reported the elaborate considerations made to identify the important actors and take up their views. Some projects thereby tried not to give a particular notion, but to encourage a discussion process among the relevant societal actors and stakeholders to draft a shared vision (e.g., AQUA, WAT). In other projects, triggering a debate was not an issue, as a broad and inclusive consensus about what to strive for quite obviously existed (e.g., LEG). In terms of interests, power and expertise, these projects' sustainability notions seemed to reflect the relevant actors' perspectives well.

\section{Characteristics of how sustainability conceptions are} handled

The identified differences with respect to handling sustainability goals can be described more precisely by distinguishing in what way sustainability notions were actually an issue the researchers engaged in on the level of the project; whether they were made explicit; how concrete they were; as well as what importance researchers ascribed to them in their projects. These characterizing properties derived from the data are denoted here as deliberation, explicitness, contextualization and relevance.

\section{Deliberation}

Whether, and to what extent, the researchers reflected upon sustainability understandings underlying their projects is 
referred to here as deliberation. Deliberation also indicates to some extent the awareness of one's own worldviews and their possible influence on a projects' conception. In projects at one extreme of the spectrum, sustainability goals had either not been reflected upon or only to a small extent. This was indicated by interviewees being unsure about the existence of a sustainability conception, by missing arguments on why a certain notion would be adequate, or by taking the meaning of sustainable development as a given or irrelevant for their work. Some interviewees took up the position that deliberating sustainability orientations was-more or less fully-delegable or excludable from research. MOUNT, for example, held that, as researchers, they could not determine a sustainability conception without the resource users on the ground. At the same time, the researchers were aware of the fact that, with respect to the defined sustainability indicators as well as the planned policy recommendations, their work still entailed certain value judgments:

"What we show is in principle what are the trends and what can be done to make sure (...) the land is still used everywhere, milk and meat are produced, but we don't judge it in the sense of what is more sustainable. (...) Well, it [sustainability] is of course, implicitly it is of course taken into account as well. (...) But, there is not a real sustainability discussion in our project, I don't believe that, in the sense, or regarding what needs to be done so that everything is more sustainable; we rather show the instruments that could lead to a sustainable development. And that evaluate single aspects of it" (translated from MOUNT 1, p. 19).

Projects on the other extreme of the spectrum featured sustainability conceptions that had been well reflected upon.

\section{Explicitness}

Explicitness distinguishes whether, and to what extent, the researchers explicitly stated the sustainability conception underlying a project. The sample featured a spectrum ranging from rather implicit to entirely explicit statements (cf. Table 3). Explicitly stated sustainability understandings sometimes corresponded to the researcher's personal view:

"Well I conceive sustainability always in a very comprehensive [sense], well it encompasses everything. It should encompass on the one hand like I said that one can stop this forest clearance, and that at the same time all the other aspects of sustainability are kept preserved as well" (translated from LIV, p. 8).

Comparison of the projects further revealed that explicitly stated sustainability conceptions did not necessarily imply a higher degree of deliberation.

\section{Contextualization}

Contextualization describes how strongly the sustainability conception of a project was concretized in the context of the sustainability question at issue. The identified sustainability conceptions ranged from quite distinct visions to featuring more general understandings. Indicating clear priorities for soil quality, crop yields, fertilizer use and livestock production, for instance, featured a quite specific conception (LEG). In contrast, another project quite generally referred to forest preservation, a decent standard of living of smallholders and self-determination, but barely specifyied these goals further in the context of the investigated region (PALM, cf. Table 3).

\section{Relevance}

The relevance of sustainability conceptions stands for the status the researchers attributed to sustainability-related normative aspects in their projects. The interviewed researchers that represented one end of the spectrum regarded sustainability visions to be something that would be rather insignificant for the actual research work. In contrast, those on the other end integrated questions about what could be sustainable into their projects. Researchers who regarded sustainability conceptions to be rather irrelevant for their work at the same time conceptualized them as normative frames:

"Well the point is, the sustainability aspect played a relatively small role for the realization of the project. We had a concrete research question (...) and this research question was of course completely decoupled from the sustainability aspect. And this [the sustainability aspect] then played a role when interpreting the results. So when I look at these two research sites now, and interpret the results of our measurements, it becomes clear that the [one] site was obviously overgrazed. And therefore there's the risk that-given the use is continued in the same way - a sustainable development is not ensured. (...) But sustainability per se was not our focus or object [of research]. Rather the results now available can be put into the context of sustainability and the project's results can be integrated into sustainable land use. But that's a bigger picture and we are only a small piece of it" (translated from CARB 1, p. 10).

In such cases, the sustainability vision concerned, for example, the overall context and motivation into which the research was embedded in (POLL). This greater visionbeing based on a longer-term collaborative research effort in the area-in this case served as a normative frame for the $\mathrm{PhD}$ project. Thus, both the contents of this vision and 
the single actors' perspectives on sustainability goals were not deliberated at the level of this specific study, but they were in the wider research program within which the project was embedded. Integrating various crucial local stakeholders' visions and priorities into the project was, for instance, realized on the basis of scenarios provided by the research project, which in turn allowed exchange and discussion of different notions and priorities in participative workshops (WAT).

\section{Discussion: Implications for moving towards adequate sustainability conceptions of research projects}

Implications of relating research to normative concepts like sustainable development

Sustainability goals and scientific research can be regarded as being decoupled. In this case, there is, however, still the risk of referring to specific sustainability visions and thus implicitly clearly taking a certain position in this regard. In the investigated sample, this happened notably when putting the research into the wider societal problem context, i.e., in the stages of both project development and results interpretation. Thus, outsourcing sustainability orientations apparently does not guarantee that respective value judgments do not re-enter by the back door. The findings of this article suggest that research that aims to support societal change towards sustainable development cannot avoid making an effort to clarify how normative goals can be dealt with. Trying to be value-free is thus too simplistic. Researchers that treat sustainability as a normative frame may furthermore be tempted to regard the meaning of sustainable development as being obvious and shared by the relevant actors. However, such shared understandings need to be handled with care, as they are typically restricted to a certain community or "thought collective" as Fleck put it (Fleck 1979). Thus they are not necessarily clear to outsiders (Pohl et al. 2010b). Researchers who include sustainability orientations in their work and embrace value-related questions for their part risk taking a position themselves.

The results further suggest that, in order to consider actors' and stakeholders' perspectives on sustainable development, these need to be known or to be readily identifiable. This is of course not always the case. The researchers that encountered such a situation coped with it in two different ways: they either turned investigating people's positions into an object of research, or approached stakeholders' perspectives in a participatory process, i.e., by means of involving community members in the research. Thus, considering relevant actors' perspectives does not necessarily demand participatory research approaches. Whether applying participatory approaches is necessary and possible thus seems to depend on the problem situation, e.g. for the state of the discussion and the degree of consensus among important actors, as well as, most importantly, on how familiar scientists are with the different positions.

Basic guidelines for evaluating sustainability conceptions of research projects

The empirically identified characteristics of how sustainable development is conceived and handled in research projects relate to the adequacy of such conceptions in different respects. The following sections illustrate in what ways they can support evaluating sustainability conceptions of research projects additional to the two basic requirements derived from the Brundtland definition, namely to (1) consider the overall meaning of sustainable development, as well as (2) reflect relevant actors and stakeholders' perspectives on sustainable development (Fig. 1).

\section{Deliberate how to conceptualize sustainable development}

Checking whether the position a project takes is in line with the overall meaning of sustainable development while covering relevant people's visions, and where required adapting it clearly necessitates deliberation. Reflecting on underlying norms and principles also allows one's own assumptions and positions to be revealed, and is thus a fundamental precondition for ascertaining the appropriateness of sustainability goals.

\section{Make sustainability conceptions explicit}

Putting an underlying sustainability conception up for discussion facilitates assessing its adequacy. However, this is possible only when it is made explicit. Explicitness, i.e., whether a sustainability conception is explicitly stated or implicitly resonating can thus be regarded as a second precondition for striving for appropriately conceiving sustainability goals.

\section{Check the contextualization of the sustainability conception}

Contextualization is not a direct indicator for the appropriateness of sustainability conceptions. Neither is a quite distinct framing of sustainable development in a project's context more adequate than a more general one. However, the issue is of importance insofar as:

- Projects featuring conceptions that are strongly specified in the context of the sustainability challenge, i.e., that are strongly contextualized, have to particularly 


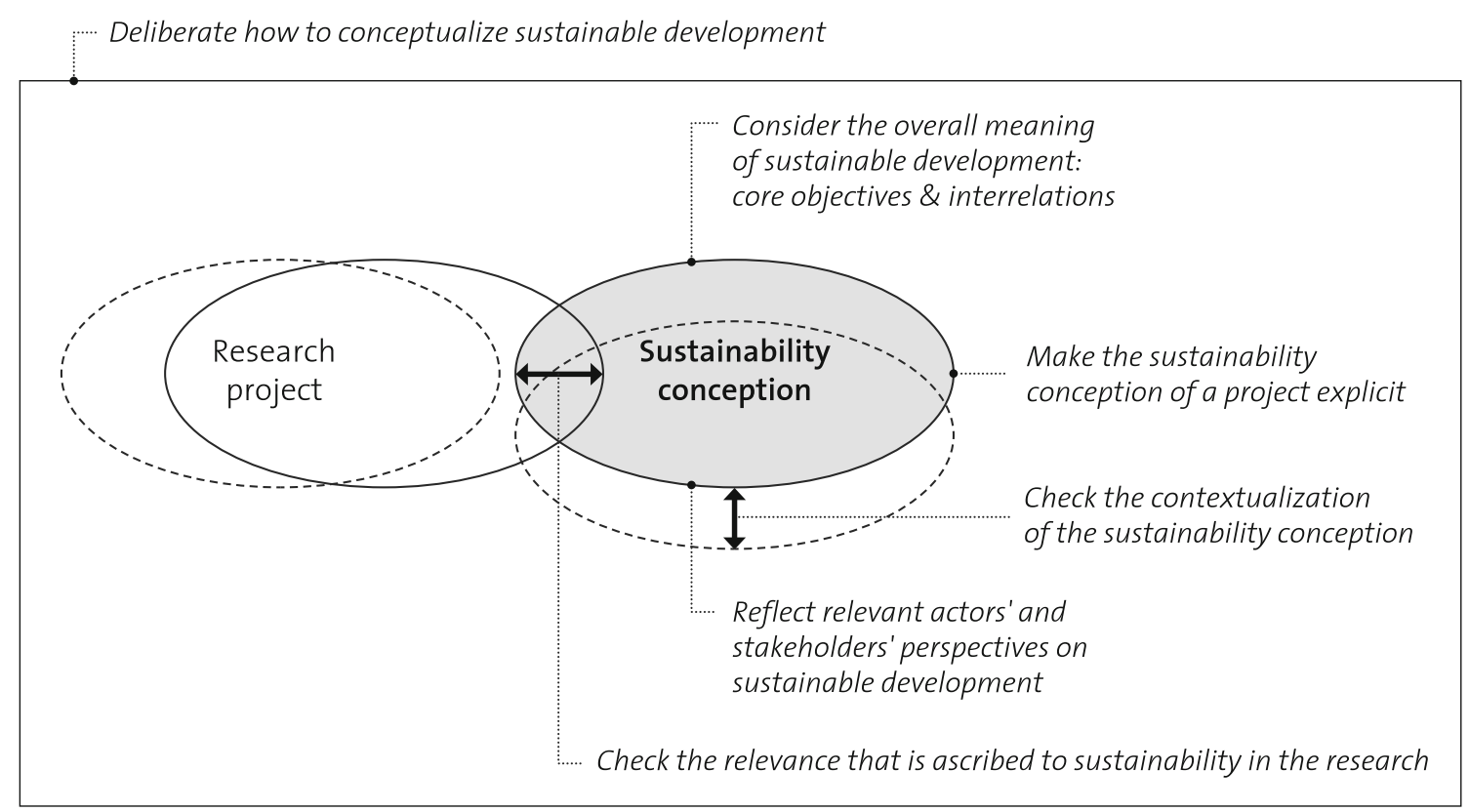

Fig. 1 Basic guidelines for evaluating sustainability conceptions of research projects comprise: considering the overall meaning of sustainable development and reflecting relevant actors and stakeholders' perspectives on sustainable development (basic requirements);

pay attention to not losing sight of the overall objectives of sustainable development; and, on the other hand

- Projects referring to general conceptions may at some point have to look into how these conceptions can be turned into more specific goals. In doing so, broadly approved general notions need to become more distinct visions that are shared by the relevant actors and stakeholders. Embracing these stakeholder perspectives becomes particularly important here.

Thus, the degree of contextualization differentiates aspects that are relevant for checking the adequacy of sustainability conceptions depending on the case.

\section{Check the relevance that is ascribed to sustainability in the research}

The relevance that projects ascribe to sustainability goals also has a differentiating function with respect to the adequacy of sustainability conceptions of research projects:

- Projects that ascribe to sustainability understandings the role of an external frame need to assess whether this is legitimate, which may include checking the contents of such understandings and assessing their appropriateness;

- Projects that integrate questions about what sustainability entails in a certain context into the research work must be careful about how to handle the respective notions without introducing the researchers' own position into the project. deliberating underlying sustainability conceptions and making them explicit (instrumental preconditions); as well as checking the contextualization of the sustainability conception and its relevance to the project (differentiating function)

Thus, the relevance that is attributed to sustainability conceptions by the scientists differentiates possible traps or particular issues (with respect to the legitimation of a chosen model) that need to be considered in appraising their adequacy.

\section{Significance of the guidelines}

Whereas deliberating underlying sustainability conceptions and making them explicit is instrumental for ascertaining or improving their adequacy, checking the contextualization of the sustainability conception as well as its relevance in the project lead to differentiating considerations that highlight issues of particular importance in specific cases. These considerations might form a useful extension of the two basic requirements of verifying the conception to which one refers with respect to (1) the addressed core objectives and (2) the reflected actors and stakeholders' perspectives in embracing the diversity of research for sustainable development.

\section{Conclusions}

This study has developed important attributes for characterizing the different ways in which research can frame and relate to societal visions like sustainable development. The identified guidelines-deduced from theoretical adequacy requirements and empirically identified characteristics 
describing how a set of Swiss land use research dealt with sustainability objectives-form a sound starting point for evaluating sustainability conceptions to which scientific studies refer. The results of this study suggest that evaluating sustainability conceptions of research projects implies at least an extra effort in project development, i.e., in the process of framing a sustainability problem and identifying the questions to be investigated, but can-and in many cases might have to-be extended into extra studies on people's problem perceptions, positions and power constellations. The presented considerations are based on a number of current research practices. They provide a grounded conceptual starting point for investigating further research approaches as well as a broader range of sustainability challenges. In addition, the developed heuristic might be inspiring not only for other scientific fields, but also for non-academic sustainabilityoriented endeavors. Last but not least, the results of this study support allowing the necessary and naturally existing diversity of shaping research for sustainable development in highly dynamic real world contexts.

Acknowledgments The author would like to thank all colleagues who took the time for being interviewed and were willing to share their views for this study. Also, the valuable inputs and support of Gertrude Hirsch Hadorn and Christian Pohl as well as the feedbacks from two anonymous reviewers are highly appreciated. Finally, the author thanks Marleen Schaefer for assisting in the transcription work. This research was funded by a grant from the Swiss National Science Foundation and supported by the Competence Center for Environment and Sustainability of the ETH Domain.

Open Access This article is distributed under the terms of the Creative Commons Attribution License which permits any use, distribution, and reproduction in any medium, provided the original author(s) and the source are credited.

\section{References}

Boyce JK (1994) Inequality as a cause of environmental degradation. Ecol Econ 11(3):169-178

Brown Weiss E (1989) In fairness to future generations; international law, common patrimony, and intergenerational equity. United Nations University and Transnational Publishers, Tokyo

Cerin P, Scholtens B (2011) Linking responsible investments to societal influence: motives, assessments and risks. Sustain Dev 19(2):71-76. doi:10.1002/sd.508

Collins HM, Evans R (2002) The third wave of science studies: studies of expertise and experience. Soc Stud Sci 32(2):235-296

Corbin JM, Strauss AL (2008) Basics of qualitative research : techniques and procedures for developing grounded theory, 3rd edn. Sage, Thousand Oaks

Creswell JW (1994) Research design-qualitative and quantitative approaches. Sage, Thousand Oaks

Denzin NK, Lincoln YS (2005) The SAGE handbook of qualitative research, 3rd edn. Sage, Thousand Oaks

Enengel B, Muhar A, Penker M, Freyer B, Drlik S, Ritter F (2012) Co-production of knowledge in transdisciplinary doctoral theses on landscape development-an analysis of actor roles and knowledge types in different research phases. Landscape Urban Plan 105(1-2):106-117

Evely AC, Fazey I, Pinard M, and Lambin X (2008) The influence of philosophical perspectives in integrative research: a conservation case study in the Cairngorms National Park. Ecol Society 13 (2): 52. http://www.ecologyandsociety.org/vol13/iss2/art52/

Fergus AHT, Rowney JIA (2005) Sustainable development: lost meaning and opportunity? J Bus Ethics 60:17-27

Fleck L (1979) Genesis and development of a scientific fact. The University of Chicago Press, Chicago

Gallie WB (1956) Essentially contested concepts. Proc Aristot Soc 56:167-198

Glaser BG, Strauss AL (1967) The discovery of grounded theory strategies for qualitative research, 4th edn. de Gruyter, New York

Grunwald A (2004) Strategic knowledge for sustainable development. The need for reflexivity and learning at the interface between science and society. Int J Foresight Innov Policy 1(1/2):150-167

Hirsch Hadorn G (1997) Webers Idealtypus als Methode zur Bestimmung des Begriffsinhaltes theoretischer Begriffe in den Kulturwissenschaften. J Gen Philos Sci 28(2):275-296

Jabareen Y (2008) A new conceptual framework for sustainable development. Environ Dev Sustain 10:179-192

Jacobs M (1999) Sustainable development as a contested concept. In: Dobson A (ed) Fairness and Futurity. Ocford University Press, Oxford, pp 21-45

Kates RW, Parris TM, Leiserowitz AA (2005) What is sustainable development? goals, indicators, values, and practice. Environment 47(3):8-21

Lafferty WM, Langhelle O (1999) Sustainable development as concept and norm. In: Lafferty WM, Langhelle O (eds) Towards sustainable development. On the goals of development-and the conditions of sustainability, Macmillan, Basingstoke, pp 1-29

Lélé SM (1991) Sustainable development: a critical review. World Dev 19(6):607-621

Merriam SB (1990) Case study research in education: a qualitative approach. Jossey-Bass, San Francisco, London

Miller TR (2013) Constructing sustainability science: emerging perspectives and research trajectories. Sustain Sci 8:279-293. doi:10.1007/s11625-012-0180-6

Mitchell RK, Agle BR, Wood DJ (1997) Toward a theory of stakeholder identification and salience: defining the principle of who and what really counts. Acad Manag Rev 22(4):853-886

Morse JM (1994) Designing funded qualitative research. In: Denzin NK, Lincoln YS (eds) Handbook of qualitative research. Sage, Thousand Oaks, pp 220-235

Patton MQ (1990) Qualitative evaluation and research methods, 2nd edn. Sage, Newbury Park, CA

Pohl C, Hirsch Hadorn G (2007) Principles for designing transdisciplinary research-proposed by the Swiss Academies of Arts and Sciences. Ökom, Munich

Pohl C, Rist S, Zimmermann A, Fry P, Gurung GS, Schneider F, Speranza CI, Kiteme B, Boillat S, Serrano E, Hadorn GH, Wiesmann U (2010a) Researchers' roles in knowledge coproduction: experience from sustainability research in Kenya, Switzerland, Bolivia and Nepal. Sci Public Policy 37(4):267-281. doi:10.3152/030234210X496628

Pohl C, Wuelser G, Hirsch Hadorn G (2010b) Nachhaltigkeitsforschung: Kompromittiert die Orientierung an der gesellschaftlichen Leitidee einer nachhaltigen Entwicklung den Anspruch als Forschungsform? In: Bogner A, Kastenhofer K, Torgersen H (eds) Inter- und Transdisziplinarität im Wandel? Neue Perspektiven auf problemorientierte Forschung und Politikberatung. Nomos, Baden-Baden, pp 123-143

Redclift M (1992) The meaning of sustainable development. Geoforum 23(3):395-403 
Robinson J (2004) Squaring the circle? Some thoughts on the idea of sustainable development. Ecol Econ 48 (4): 369-384. doi:10. 1016/J.Ecolecon.2003.10.017

Schultz J, Brand F, Kopfmuller J, Ott K (2008) Building a 'theory of sustainable development': two salient conceptions within the German discourse. Int J Environ Sustain Dev 7(4):465-482. doi:10.1504/ijesd.2008.022390

Sneddon C, Howarth RB, Norgaard RB (2006) Sustainable development in a post-Brundtland world. Ecol Econ 57(2):253-268. doi:10.1016/j.ecolecon.2005.04.013

Thompson J, Scoones I (2009) Addressing the dynamics of agri-food systems: an emerging agenda for social science research. Environ Sci Policy 12(4):386-397

van Egmond ND, de Vries HJM (2011) Sustainability: the search for the integral worldview. Futures 43(8):853-867. doi:10.1016/j. futures.2011.05.027

WCED (1987) Our common future. Oxford University Press, Oxford, New York
Weber M (1973) Die Objektivität sozialwissenschaftlicher und sozialpolitischer Erkenntnis. In: Winckelmann J (ed) Gesammelte Aufsätze zur Wissenschaftslehre. Mohr (Siebeck), Tübingen, pp 146-215

Wiek A, Ness B, Schweizer-Ries P, Brand FS, Farioli F (2012) From complex systems analysis to transformational change: a comparative appraisal of sustainability science projects. Sustain Sci 7:5-24. doi:ker10.1007/S11625-011-0148-Y

Wolf S, Eugster W, Potvin C, Turner B, Buchmann N (2011) Carbon sequestration potential of tropical pasture compared with afforestation in Panama. Glob Change Biol 17(9):2763-2780

Wuelser G, Pohl C, Hirsch Hadorn G (2012) Structuring complexity for tailoring research contributions to sustainable development: a framework. Sustain Sci 7:81-93. doi:10.1007/s11625-011-0143-3

Wynne B (1991) Knowledges in context. Sci Technol Human Values 16(1):111-121 